Original Article

\title{
STUDY OF EFFECT OF AYURVEDIC PHARMACEUTICAL PROCESSING NAMED SHODHANA AND MARANA ON THE CHEMICAL COMPOSITION AND CRYSTALLINE STRUCTURE OF METAL IRON AND IRON-CONTAINING MINERALS USING XRD AND XRF ANALYSIS
}

\author{
ADITI KULKARNI ${ }^{1}$, SYED TANVEER AHMED ${ }^{2}$, S. S. SAVRIKAR ${ }^{3}$
}

${ }^{1,3}$ Rasashastra and Bhaishjya Kalpana, Ra Podar Medical College, Dr. Annie Besant Road, Worli Mumbai 400018, ${ }^{2}$ Senior Project Assistant (Bpcl Project), Ict, Matunga | Mumbai

Email: aditi0509@gmail.com

Received: 17 May 2021, Revised and Accepted: 30 Aug 2021

\section{ABSTRACT}

Objective: This study was designed to evaluate the effect of Ayurvedic pharmaceutical procedures Shodhana and Marana on the chemical composition of the raw material.

\begin{abstract}
Methods: Iron and four iron-containing minerals were subjected to Shodhana and Marana. For Shodhana, Loha (Iron), Suvarnamakshika (Copper pyrite) and Mandura (iron slag,) were repeatedly quenched sequentially in sesamin oil, buttermilk, cow's urine, natural vinegar and herbal decoctions. Kasisa (green vitriol) was grinded in the juice of Eclipta Alba. For Marana, these materials were first grinded in prescribed liquids and then incinerated in closed earthenware caskets in measured pits. Powdered Gairika (red ochre) was roasted in Cow's ghee for its Shodhana. Samples of Loha (iron)-L1, Samanya Shodhita Loha-L2, Vishesha Shodhita Loha-L3, Loha bahsma-L4, Mandura (iron slag)-M1, Shodhita Mandura-M2, Mandura bahsma-M3, Suvarnamakshika (copper pyrite)-S1, Shodhita Suvarnamakshika-S2, Suvarnamakshika bhasma-S3, Kasisa (green vitriol)-K1, Shodhita Kasisa-K2, Kasisa bahsma-K3, Gairika (red ochre)-G1 and Shodhita gairika-G2; were studied using XRF and XRD techniques.
\end{abstract}

Results: XRD findings suggested that the Chemical nature, elemental composition and Crystaline lattice structure of each substance were altered after extensive processings. XRF studies confirmed the multi-elemental nature of the final products. Reduction in particle size and other morphological changes were observed in intermediate and finished products during each procedure.

Conclusion: The study indicates that the composition of material is altered as a result of Ayurvedic pharmaceutical processing, 'Shodhana and Marana.

Keywords: Ayurvedic drug, Shodhana, Marana, XRD, XRF, Bhasma

(C) 2021 The Authors. Published by Innovare Academic Sciences Pvt Ltd. This is an open access article under the CC BY license (https://creativecommons.org/licenses/by/4.0/) DOI: https://dx.doi.org/10.22159/ijpps.2021v13i10.42077. Journal homepage: https://innovareacademics.in/journals/index.php/ijpps.

\section{INTRODUCTION}

A branch of Ayurvedic medicine that principally deals with metallic and mineral drug preparations is known as Rasa Shastra. The drugs of Metallic and mineral origin are processed with an objective to make them edible, therapeutically effective and completely safe in therapeutic doses. Generally, a raw metallic or mineral drug substance undergoes through the following pharmaceutical procedures.

The raw material fulfilling the required criteria of selection for its use in drug preparation is usually collected from the market. The collected raw material is first made suitable for further processing like preparation of thin metal sheets or grinding the raw material to produce a powder of suitable particle size. The thin metal sheets or the metal powder as the case may be, are subjected to a pharmaceutical procedure named Shodhana [1] in terms of Ayurveda. The literal meaning of Shodhana is purification. But translation of the term Shodhana as purification produces a misperception about the objective and the real effect of the Shodhana procedure. Hence such translation should never be used. Purification in the process of Shodhana is restricted only to physical purification. It nowhere implies or achieves chemical purity of the material being processed. In addition to physical purification, the procedure softens the processed material to some extent and makes it ready for further processing. In some cases, particularly in case of some minerals which are soft in consistency like red ochre used in the present study, the softening of the material is sufficient to put the material directly to therapeutic use. In such cases the material also becomes safe for internal use in therapeutic doses following Shodhana. Metals are usually subjected to two types of Shodhana: Samanya (common for all metals) and Vishesh (specific to a metal to be used with a specific therapeutic objective). All metals and minerals which are hard in consistency need to undergo one more pharmaceutical procedure named as Marana [2] following Shodhana.

The pharmaceutical process of Shodhana includes procedures like heating the material to red heat and then quenching it in prescribed liquids till the material under process achieves the required quality. The pharmaceutical process of Marana to be followed after Shodhana includes incineration of the material obtained as an end product of the process of Shodhana. The material obtained from Shodhana is first wet ground with prescribed medicinal substances either liquid or solid or both, depending on the prescribed method. The grinding is continued till the material is converted into a dough. The dough so produced is used to prepare small cakes of suitable size. The cakes so produced are dried and put in a closed circular earthenware container known as casket (Sharava Samputa in terms of Ayurveda) and then subjected to incineration in a measured pit using dried cow dung cakes as fuel. The process of incineration is repeated till a product of desired quality is obtained. The product obtained after completion of incineration is known as Bhasma. Both these processes named Shodhana and Marana bring about significant change in the constitution of the processed material. Naredran N. et al. (2012) have shown the reducing effect of Gallic acid from Horse gram on Loha Bhasma during Marana [3]. In the present study the metal Loha (metal Iron) and minerals Gairika (red ochre), Kasisa (ferrous sulphate), Suvarnamakshika(Copper pyrite) and Mandur (iron slag, ferric oxide) were subjected to their respective Shodhana and Marana to obtain their therapeutically useful drug forms named as Bhasma. These Bhasmas and their intermediates obtained as end products following their Shodhana and Marana were subjected to XRD and XRF analysis to study the effect of these procedures on the constitution of the processed raw metals and minerals. 


\section{MATERIALS AND METHODS}

\section{Collection of raw materials}

The raw material i.e. Loha (metal Iron), Gairika (red ochre), Kasisa(green vitriol: ferrous sulfate), Suvarnamakshika (Copper pyrite), and Mandura (iron slag: ferric oxide) fulfilling the expected quality as described in the classical texts [4] were collected from the local market.

The raw materials so collected were subjected to their respective Shodhana and Marana procedures. The end products obtained following completion of both the procedures were Loha Bhasma, Mandura Bhasma, Suvarnamakshika Bhasma, Kasisa Bhasma, and Shuddha Swarna Gairika.

\section{Pharmaceutical processing}

Loha (metal Iron) was subjected to the following pharmaceutical processing to obtain Loha Bhasma.

\section{Shodhana and marana of loha}

Loha Bhasma preparation includes the following steps.

\section{Loha samanya shodhana}

Moderately fine powder of Loha was heated till it gets red hot and quenched three times each into Sesame oil, buttermilk, kanjika (sour rice gruel), cow's urine, and decoction of Kulattha (horse gram), respectively [5].

\section{Loha vishesh shodhana}

After Following Samanya Shodhana, Vishesh Shodhana was performed. Loha choorna was heated till it gets got red hot and quenched seven times in the decoction of Triphala prepared in Gomutra (cow's urine). By this method, Shuddha Loha Choorna was obtained [6].

\section{Loha marana}

After Following Loha Shodhana, Shuddha Loha was subjected to Loha Marana. It was done in three steps.

\section{Loha bhanupaka}

Shuddha Loha choorna was soaked in specially prepared Triphala decoction to make it produce its slurry. The mixture was kept in an open earthen plate. This plate was exposed to blazing sunlight till all the liquid got evaporated. The process was repeated 7 times [7].

\section{Loha sthalipaka}

Loha choorna processed in Bhanupaka was washed with water. It was then mixed in specially prepared Triphala decoction (q. s.) to produce a slurry. The mixture was then subjected to heating on a high flame. This was continued till all the moisture got evaporated. The process is known as Loha Sthalipaka [8].

\section{Loha putpaka}

Loha Choorna was obtained as an end product of Bhaupaka followed by Sthalipaka, was washed with water and then ground well with specially prepared Triphala decoction to produce a soft dough. Thin flat pellets from this dough were prepared and dried. They were arranged and placed in a closed circular earthenware container known as Sharava samputa (casket) and then subjected to incineration in a measured pit named Gajaputa, using dried cow dung cakes as fuel. The process was repeated till the desired quality Bhasma was obtained [9].

Mandura (iron slag) was subjected to the following procedures to obtain mandura bhasma

\section{Shodhana of mandura}

Raw Mandura (iron slag) lumps were procured from the market. They were heated till they got red hot. Thereafter, $\mathrm{n}$ they were quenched in the decoction of Triphala 21 times. This decoction was prepared by boiling Triphala in cow urine instead of water. This process yielded small fragile pieces of Shuddha Mandura [10].

\section{Marana of mandura}

Shuddha Mandura obtained as an end product of the Shodhana process was subjected to wet grinding with Aloe juice (Aloe barbadensis) to produce a soft dough. Thin flat pallets from this dough were prepared and dried. They were arranged and placed in a closed circular earthenware container known as Sharava samputa (casket) and then subjected to incineration in a measured pit named Gajaputa, using dried cow dung cakes as fuel. The process was repeated till the desired quality Bhasma was obtained [11].

Suvarnamakshika (copper pyrite) was subjected to the following procedures to obtain Suvarnamakshika Bhasma.

Preparation of Suvarna makshik Bhasma includes the following steps.

\section{Shodhana of suvarna makshika}

Raw Suvarnamakshika was procured directly from Khetri Mines Rajsthan.

The lumps were subjected to the Shodhana process by quenching them in Triphala decoction 7 times. This process yielded Shuddha Suvarnamakshika in the form of brittle pieces [12].

\section{Marana of suvarna makshika}

Shuddha suvarmnamakshika was mixed with castor oil (q. s.) to produce a slurry. This slurry was subjected to heating in an open iron pan till all the oil part was evaporated. Oil catches fire during the process.

The material obtained as an end product of the above-mentioned procedure was subjected to wet grinding with lemon J juice to produce a soft dough. Thin flat pallets from this dough were prepared and dried. They were arranged and placed in a closed circular earthenware container known as Sharava samputa (casket) and then subjected to incineration in a measured pit named Gajaputa, using dried cow dung cakes as fuel. The process was repeated till the desired quality Bhasma was obtained [13].

Kasisa(green vitriol: ferrous sulfate) was subjected to the following procedures to obtain Kasisa a Bhasma

Preparation of Kasisa Bhasma includes the following steps.

\section{Kasisa shodhana}

Kasisa Choorna was procured from the local market. It was subjected to wet grinding with a sufficient quantity of juice of Bhringraj (Eclipta Alba) in a quantity sufficient to soak and immerse the Kasisa powder in it completely. The mixture was wet ground firmly till all the powder of Kasisa gets dried by grinding. This process was repeated three times consecutively. Thus Shuddha Kasisa was obtained as an end product of this grinding in the form of very fine powder [14].

\section{Kasisa marana}

Shuddha Kasisa obtained as an end product of the Shodhana process was wet ground with a sufficient quantity of lemon juice to produce a soft dough. Thin flat pallets from this dough were prepared and dried. They were arranged and placed in a closed circular earthenware container known as Sharava samputa (casket) and then subjected to incineration in a measured pit named Gajaputa, using dried cow dung cakes as fuel. The process was repeated till a desired quality of Bhasma was obtained [15].

Gairika (red ochre) was subjected to the following procedures to obtain Shuddha Gairika

This compound is not used in Bhasma form. Gairika is used after Shodhana only. Gairika powder was mixed with Cows ghee taken in 1/8th of its measure. Further, it was roasted on mild heat, till ghee mixed in Gairika powder disappears by frying and a freeflowing powder of Gairika is obtained. This processed Gairika is used as medicine. This is called Shuddha Gairika [16]. 
Table 1: Schematic representation of processing's of Iron metal and other Iron containing drugs

\begin{tabular}{l}
\hline Processing \\
\hline The Raw Loha---Samanya Shodhana-----Vishesh Shodhana-----Bhanupaka---Sthalipaka------Putapaka-----Loha Bhasma. \\
Raw Mandura------Shodhana of Mandura----Marana of Mandura---Mandura Bhasma \\
Raw Suvarnamakshika------Shodhana of Suvarnamakshika----Marana of Suvarnamakshika----Suvarnamakshika Bhasma \\
Raw Kasisa------Shodhana of Kasisa-------Marana of Kasisa-----Kasisa Bhasma. \\
Raw Gairika-------Shodhana of Gairika----Shuddha Swarna Gairika. \\
\hline
\end{tabular}

Table 2: Medium used for Shodhana and Marana procedures of each drug, all the materials were tested for their authenticity, following Indian standards and in-house standards

\begin{tabular}{|c|c|c|c|c|}
\hline Drug & $\begin{array}{l}\text { Drugs used for } \\
\text { Shodhana }\end{array}$ & Preparation of medium & $\begin{array}{l}\text { Drugs used } \\
\text { for Marana }\end{array}$ & Preparation of medium \\
\hline \multirow[t]{5}{*}{$\begin{array}{l}\text { Loha } \\
\text { Samanya } \\
\text { Shodhana }\end{array}$} & Sesame oil, & Procured from local market & $\begin{array}{l}\text { Bhanupaka } \\
\text { Triphala } \\
\text { Decoction }\end{array}$ & $\begin{array}{l}\text { Course powder of Triphala weighing } \\
\text { equal to the quantity of Lohaand passing } \\
\text { through sieve no } 44 \text { was mixed with } \\
\text { double parts of water, boiled, and reduced } \\
\text { to } 1 / 4 \text { th of the original quantity. }\end{array}$ \\
\hline & Buttermilk, & $\begin{array}{l}\text { Cow's milk inoculated with curd. Next day curd was } \\
\text { mixed with water }(2: 1) \text { and churned. Butter was } \\
\text { removed and buttermilk was used. }\end{array}$ & $\begin{array}{l}\text { Sthalipaka } \\
\text { Triphala } \\
\text { Decoction }\end{array}$ & $\begin{array}{l}\text { Course powder of Triphala weighing } \\
\text { triple to the quantity of Loha a and } \\
\text { passed in g through sieve no } 44 \text { was } \\
\text { mixed with double parts of water, boiled, } \\
\text { and reduced to } 1 / 4^{\text {th }} \text { of the original } \\
\text { quantity. }\end{array}$ \\
\hline & Cow's Urine & Procured from local source. & $\begin{array}{l}\text { Putpaka } \\
\text { Triphala } \\
\text { Decoction }\end{array}$ & $\begin{array}{l}\text { Course powder of Triphala passed ing } \\
\text { through sieve no } 44 \text {, was mixed with } 16 \\
\text { parts of water, boiled, and reduced to } \\
1 / 8^{\text {th }} \text { of the original quantity. }\end{array}$ \\
\hline & Kanji & $\begin{array}{l}\text { Parboiled Precooked rice was cooked and mixed with } \\
3 \text { parts of water. The mixture was kept aside for } 7 \mathrm{~d} \text {. } \\
\text { It was filtered after that and the filtrate taken for the } \\
\text { process. }\end{array}$ & & \\
\hline & $\begin{array}{l}\text { Decoction of } \\
\text { Horse Gram }\end{array}$ & $\begin{array}{l}\text { Horse gram (Dolichos biflorus) seeds were soaked } \\
\text { overnight in water. They were cooked in } 16 \text { times of } \\
\text { water till the water was reduced to } 1 / 8^{\text {th }} \text { of the } \\
\text { original quantity. Decoction was used after filtration. }\end{array}$ & & \\
\hline Loha & Triphala & Course powder of Triphala passing through sieve no & & \\
\hline $\begin{array}{l}\text { Vishesh } \\
\text { Shodhana }\end{array}$ & decoction & $\begin{array}{l}44 \text { was mixed with } 16 \text { parts of water, boiled, and } \\
\text { reduced to } 1 / 8^{\text {th }} \text { of the original quantity. }\end{array}$ & & \\
\hline Mandura & $\begin{array}{l}\text { Triphala } \\
\text { decoction }\end{array}$ & $\begin{array}{l}\text { Course powder of Triphala passing through sieve no } \\
44 \text { was mixed with } 16 \text { parts of cow's urine, boiled, } \\
\text { and reduced to } 1 / 8^{\text {th }} \text { of the original quantity. }\end{array}$ & $\begin{array}{l}\text { Aloe Vera } \\
\text { Juice }\end{array}$ & Juice expressed from Aloe Vera leaves. \\
\hline Kasisa & $\begin{array}{l}\text { Juice extract of } \\
\text { Eclipta Alba }\end{array}$ & Juice is expressed from fresh Eclipta Alba leaves. & Lemon Juice & $\begin{array}{l}\text { Expressed juice from Lemon (Citrus } \\
\text { Acida Fruits }\end{array}$ \\
\hline \multirow[t]{2}{*}{$\begin{array}{l}\text { Suvarna } \\
\text { Makshika }\end{array}$} & $\begin{array}{l}\text { Triphala } \\
\text { decoction }\end{array}$ & $\begin{array}{l}\text { Course powder of Triphala passing through sieve no } \\
44 \text { was mixed with } 16 \text { parts of water, boiled, and } \\
\text { reduced to } 1 / 8^{\text {th }} \text { of the original quantity. }\end{array}$ & Castor oil & Procured from local market. \\
\hline & & & Lemon Juice & $\begin{array}{l}\text { Expressed juice from Lemon (Citrus } \\
\text { Acida Fruits }\end{array}$ \\
\hline Gairika & Cow's ghee & Procured from the Market & - & - \\
\hline
\end{tabular}

After such an extensive procedure of Shodhana and Marana the following samples were withdrawn for the study.

Table 3: The samples collected for XRD and XRF studies at different stages of pharmaceutical processing

\begin{tabular}{|c|c|c|c|}
\hline Name of the material & Samples taken & Description & Analysis Performed \\
\hline \multirow[t]{4}{*}{ Iron } & L1 & Raw Loha & XRD \\
\hline & $\mathrm{L} 2$ & After Samanya Shodhana & XRD \\
\hline & L3 & After Vishesh Shodhana & XRD \\
\hline & $\mathrm{L} 4$ & Bhasma (Calx) & XRD and XRF \\
\hline \multirow[t]{2}{*}{ Gairika } & G1 & Raw Gairika & XRD \\
\hline & G2 & Shuddha Gairika & XRDand XRF \\
\hline \multirow[t]{3}{*}{ Suvarna makshik } & S1 & Raw Suvarna makshika & XRD \\
\hline & $\mathrm{S} 2$ & Shuddha Suvarna makshika & XRD \\
\hline & S3 & Bhasma of Suvarna makshika & XRDand XRF \\
\hline \multirow[t]{3}{*}{ Kasisa } & K1 & Raw Kasisa & XRD \\
\hline & $\mathrm{K} 2$ & Shuddha Kasisa & XRD \\
\hline & K3 & Bhasma of Kasisa & XRDand XRF \\
\hline \multirow[t]{3}{*}{ Mandura } & M1 & Raw Mandura & XRD \\
\hline & M2 & Shuddha Mandura & XRD \\
\hline & M3 & Bhasma of Mandura & XRDand XRF \\
\hline
\end{tabular}


Description of XRD studies-Powder X-ray diffraction spectra were recorded at $298 \mathrm{~K}$ on a Bruker D8-Ray diffractometer, with a $0.2 \mathrm{step}$ size at $0.0 \mathrm{a} 2$ theta/min scanning speed, $40 \mathrm{kV}$ voltage, $40 \mathrm{~mA}$ current between scanning angles 5 to 90 ( 2 thetas).
Description of XRF studies-X-Ray fluorescence was done at Varsha Bullion Lab in Mumbai.

\section{RESULTS}

The results were recorded as follows.

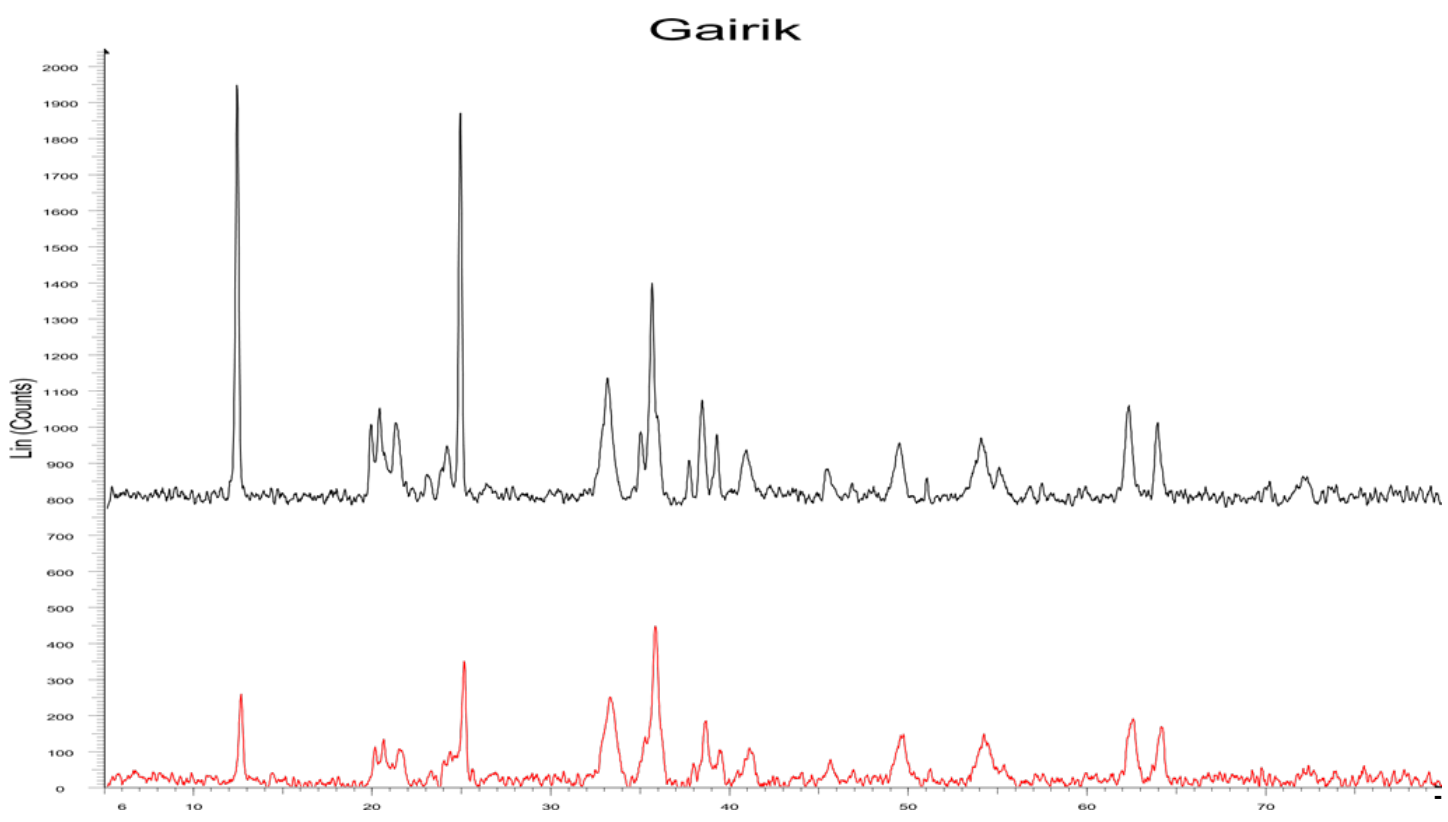

Fig. 1: XRD analysis of raw Gairika and shuddha Gairika revealed interesting findings

\section{2-Theta-scale}

Gairika-File: G1. raw-Type: 2Th/Th locked-Start: $5.000^{\circ}$-End: 80.005 ${ }^{\circ}$-Step: $0.021^{\circ}$-Step time: 17.7 s-Temp.: $25^{\circ} \mathrm{C}$ (Room)-Time Started: 10 s-Anode: Cu-WL1: Operations: Y Scale Add 792 | Smooth 0.150 | Background 1.000,1.000 | Import

G2-File: G2. raw-Type: 2Th/Th locked-Start: $5.000^{\circ}$-End: $80.005^{\circ}$ Step: $0.021^{\circ}$-Step time: $17.7 \mathrm{~s}$-Temp.: $25^{\circ} \mathrm{C}$ (Room)-Time Started: 9 s-Anode: Cu-WL 1: 1.540perations: Smooth 0.150 | Background $1.000,1.000$ | Import

G1 and G2 have their X-ray characteristic peaks at 2-theta values of $12,21,25,33,36,49$, and 54 , which correspond to the lattice indices of $111,220,222,104,110,024$, and 116 , respectively. The crystallinity of the compounds based on XRD analysis shows similarity with Iron Tin Oxide (01-088-0434 (N)) with Rhombohedral lattice. There is no remarkable change in crystallinity of Gairikaa due to processing from G1 to G2. The crystalline phase remains Rhombohedral. This may be because of the roasting of Gairika with ghee. The process doesn't involve intense heat. Hence the crystalline phase didn't change. Percentage crystallinity is decreased in G2 because of heat treatment. The XRF studies revealed that Shuddha Gairika contains $35.8 \%$ of ferric oxide, $34.3 \%$ of silica, $\mathrm{Al} 203$ in $28.4 \%$. Also, there are some trace elements found in G2.

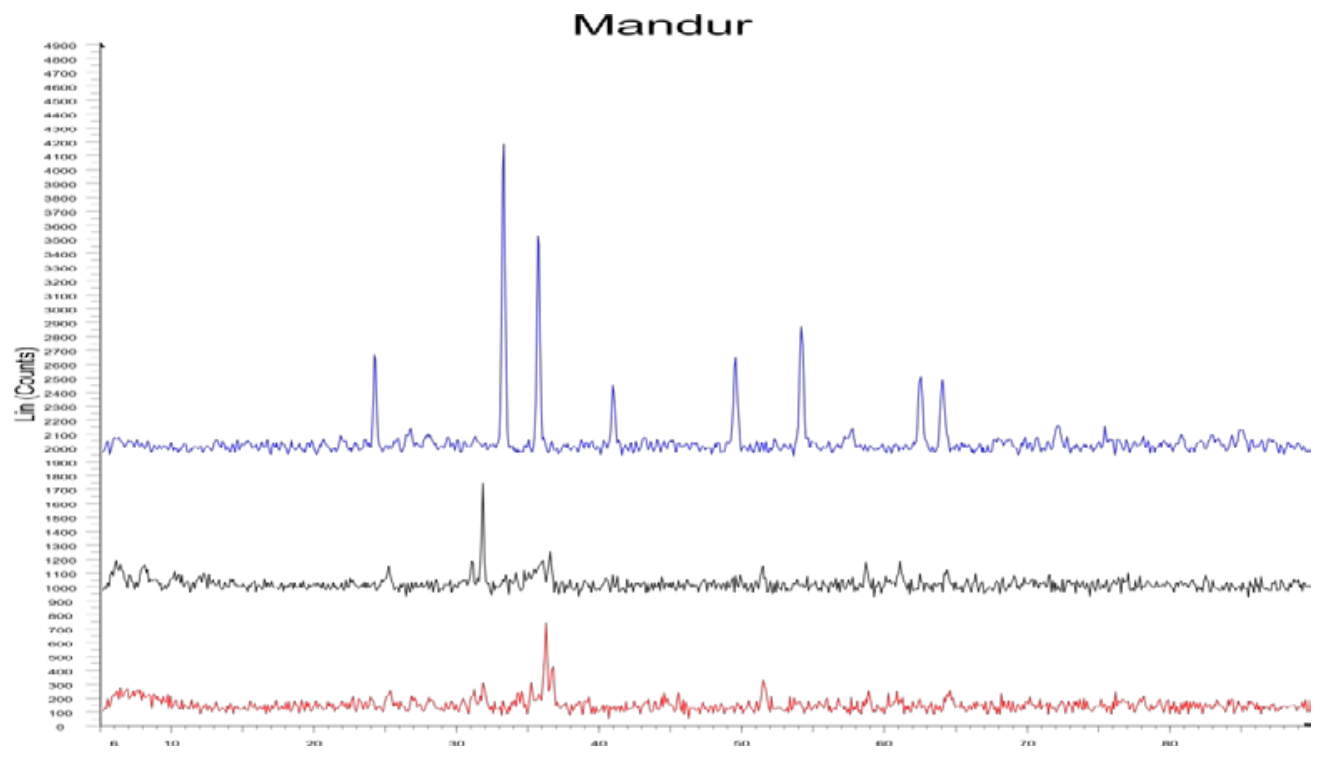

Fig. 2: The XRD analysis findings in case of Mandura are as follow 
2-Theta-Scale Mandur-File: M1. raw-Type: 2Th/Th locked-Start: 5.000 ${ }^{\circ}$-End: $90.023^{\circ}$-Step: $0.100^{\circ}$-Step time: $35.4 \mathrm{~s}$-Temp.: $25^{\circ} \mathrm{C}$ (Room)-Time Started: 12 s-Anode: Cu-WL1 Operations: Y Scale Add 125 | Smooth 0.150 | Background 1.000,1.000 | Import

M2-File: M2. raw-Type: 2Th/Th locked-Start: 5.000'-End: $90.023^{\circ}$ Step: $0.100^{\circ}$-Step time: $35.4 \mathrm{~s}$-Temp.: $25^{\circ} \mathrm{C}$ (Room)-Time Started: 10 s-Anode: Cu-WL 1: 1.50perations: Y Scale Add 292| Y Scale Add 708 | Smooth 0.150 | Background 1.000,1.000 | Import

M3-File: M3. raw-Type: 2Th/Th locked-Start: 5.000-End: $90.039^{\circ}$ Step: $0.080^{\circ}$-Step time: 35.4 s-Temp.: $25^{\circ} \mathrm{C}$ (Room)-Time Started: 12 s-Anode: Cu-WL 1: 1.5 Operations: Y Scale Add-1000 | Y Scale Add 1000 | Y Scale Add 1000 | Y Scale Add 1000 | Smooth 0.150 | Background 1.000,1.000 | Import \
The XRD analysis of Mandura reveals the structure of the compound as Orthorhombic with major characteristic peaks matching with Iron Silicate-Fe2SiO4 (M1 and M2). Major XRD peaks for Mandura are observed at 25, 32, 35, 36, and 52 two-theta values correspond to 111 , $130,131,112$, and 222 respectively. The crystalline phase change was observed from Orthorhombic (M1 and M2) to Rhombohedral (M3). The crystalline phase change is due to intense treatment of heat and trituration. Even the peaks are found more intense in M3 than M1 and M2. The major peaks observed for M2 are at 24, 33, 36, 41, 49, and 54 two-theta values corresponding to hkl values of $012,104,110,113$, 024, and 211 respectively. The amount of crystallinity also changes from M1 to M3. The XRF studies of Mandura Bhasma showed the presence of $58.3 \%$ of ferric oxide, $19.6 \%$ of silica, $11.3 \%$ of Alumina, and the rest of the other elements like $\mathrm{K}, \mathrm{Ca}, \mathrm{S}, \mathrm{P}$, etc.

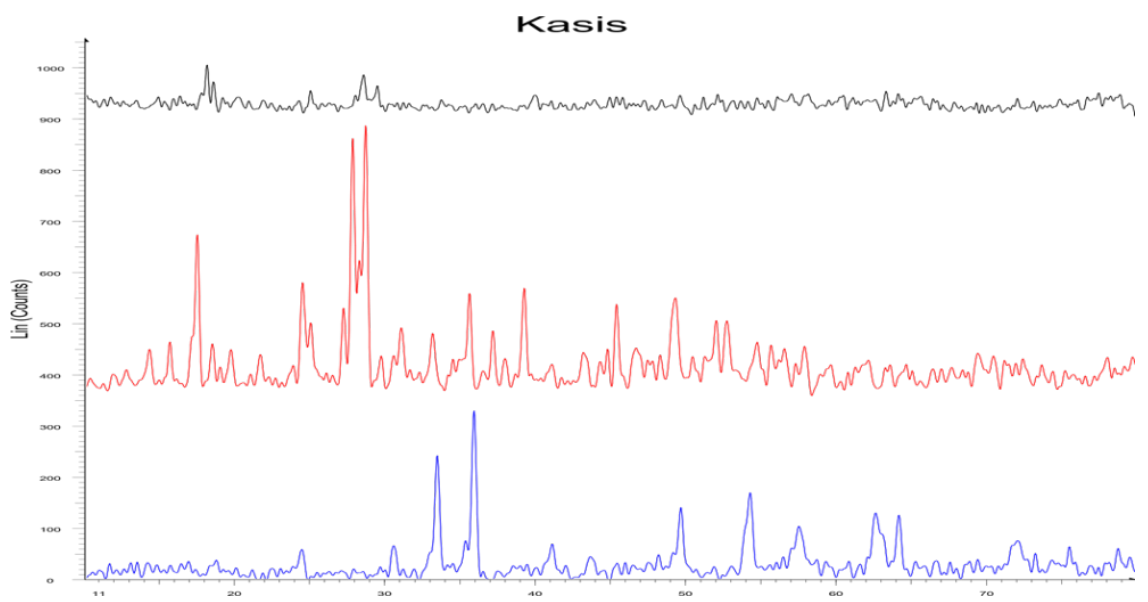

Fig. 3: Results of XRD studies of Kasisa were as follows

Kasisa-File: K_1. raw-Type: 2Th/Th locked-Start: $5.000^{\circ}$-End: 80.005 ${ }^{\circ}$-Step: $0.021^{\circ}$-Step time: 35.4 s-Temp.: $25{ }^{\circ} \mathrm{C}$ (Room)-Time Started: 14 s-Anode: Cu-WL1:Operations: Y Scale Add 375 | Y Scale Add 542 | Smooth 0.150 | Smooth 0.150 | Smooth 0.150 | Smooth 0.150 | Background 1.000,1.000 | Import

K2-File: K2. raw-Type: 2Th/Th locked-Start: $10.000^{\circ}$-End: $89.995^{\circ}$ Step: $0.021^{\circ}$-Step time: 35.4 s-Temp.: $25^{\circ} \mathrm{C}$ (Room)-Time Started: 9 s-Anode: Cu-WL1: 1.5 Operations: Y Scale Add-42 | Y Scale Add 417 | Smooth 0.150 | Smooth 0.150 | Smooth 0.150 | Smooth 0.150 | Smooth 0.150 | Smooth 0.150 | S

K3-File: K3. raw-Type: $2 \mathrm{Th} / \mathrm{Th}$ locked-Start: $10.000^{\circ}$-End: $89.995^{\circ}$ Step: $0.021^{\circ}$-Step time: $35.4 \mathrm{~s}$-Temp.: $25^{\circ} \mathrm{C}$ (Room)-Time Started: 14 s-Anode: Cu-WL1: 1. Operations: Smooth 0.150 | Smooth 0.150 |
Smooth 0.150 | Smooth 0.150 | Smooth 0.150 | Smooth 0.150 | Smooth 0.150 | Smooth 0.150 | Smooth

The Peaks of XRD are matching with Iron Sulphate Hydrate (K1), Iron hydroxide sulfate (K2), and Iron tin oxide (K3). The crystalline phase change was observed from Monoclinic (K1) to Orthorhombic (K2) to Rhombohaxes (K3). The crystalline phase change is due to the intense treatment of heat and grinding. Even the peaks are found more intense in K3 than K1 and K2. Peaks at the 2-theta value of 17, 25, 28, and 31 correspond to K2 with indices values of $101,002,102$, and 112 , respectively. K3 has major XRD characteristic peaks at $24,33,36,41,50$, and 54 with indices of $012,104,110,113,024$, and 116 , respectively. The amount of crystallinity also changes from K1 to K3. The XRF studies showed the presence of $93.2 \%$ of ferric oxide, $1.22 \%$ of silica, and the rest of the other elements like K, Ca, S in Kasisa Bhasma.

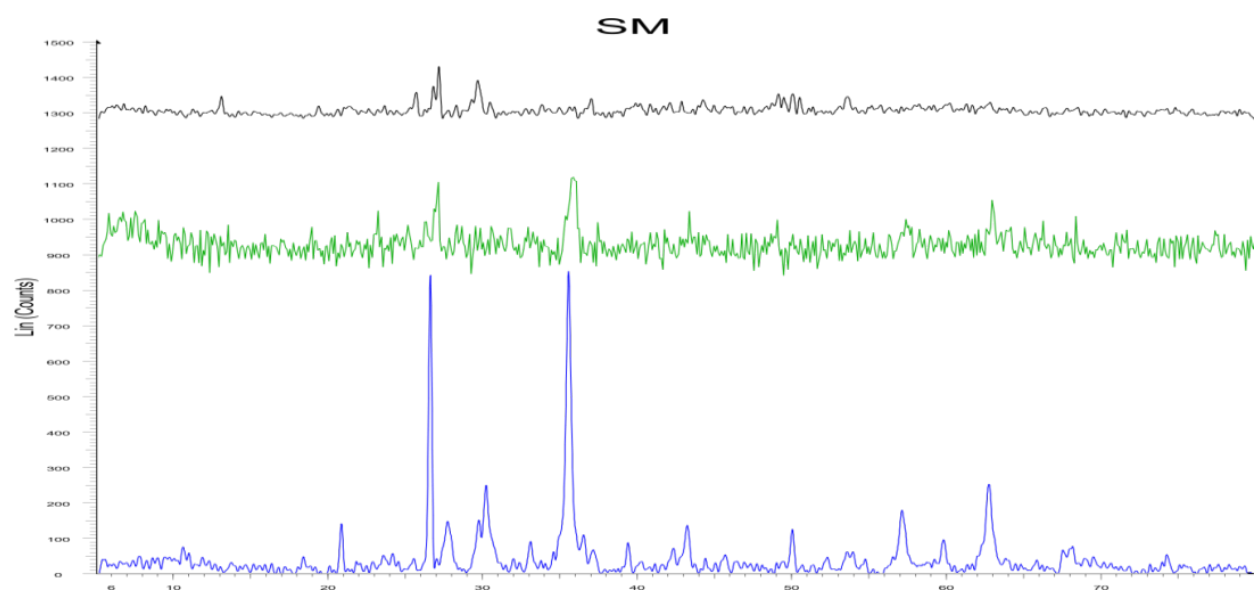

Fig. 4: Results of XRD studies of suvarna makshik were as follows 


\section{2-Theta-scale}

SM-File: S1. raw-Type: 2Th/Th locked-Start: $5.000^{\circ}$-End: $80.005^{\circ}$ Step: $0.021^{\circ}$-Step time: $17.7 \mathrm{~s}$-Temp.: $25^{\circ} \mathrm{C}$ (Room)-Time Started: 9 s-Anode: Cu-WL 1: 1.540perations: Scale Add 500 | Y Scale Add 792 | Smooth 0.150 | Smooth 0.150 | Background 1.000,1.000 | Import

S2-File: S2. raw-Type: 2Th/Th locked-Start: $5.000^{\circ}$-End: $90.023^{\circ}$ Step: $0.100^{\circ}$-Step time: 35.4 s-Temp.: $25^{\circ} \mathrm{C}$ (Room)-Time Started: 10 s-Anode: Cu-WL 1: 1.50perations: Y Scale Add 917 | Smooth 0.150 | Smooth 0.150 | Background 1.000,1.000 | Import

S3-File: S3. raw-Type: 2Th/Th locked-Start: $5.000^{\circ}$-End: $80.005^{\circ}$ Step: $0.021^{\circ}$-Step time: $17.7 \mathrm{~s}$-Temp.: $25^{\circ} \mathrm{C}$ (Room)-Time Started: 9 s-Anode: Cu-WL 1: 1.54 Operations: Smooth 0.150 | Smooth 0.150 | Background 1.000,1.000 | Import

The XRD studies on raw, intermediate Swarnamkashika and Swarnamkashika Bhasma revealed the following results. XRD analysis of Swarnamkashika Bhasma (S3) reveals the major XRD peaks at 2-theta values of $18,39,35.5,43,57$, and 63 , which are matching accurately with the XRD pattern of copper iron oxide having indices at $111,220,311,400,511$, and 440 for respective peaks. The peaks in XRD are matching with the Copper iron sulfide (S1), Copper manganese oxide (S2), and copper-iron oxide (S3). The crystalline phase change is observed as Orthrorhombic (S1) to Cubic (S2) and Cubic (S3).

(Peaks for S1-20, 25.5, 27, 30, and 49 corresponds to 121, 101, 130, 012, and 330, respectively.)

(Peaks for S2 at 19, 31, 36, 46, 54, 58 and 64 corresponds to $111,220,311,331,442,511$, and 440)

S3 is more crystalline compared to S2 and S1. The peaks are also sharp and intense. The XRF studies of Swarnamakshika Bhasma (S3), showed the presence of ferric oxide $29.9 \%$, Sio2 $46.3 \%$, CuO 3.6\%. The rest of the elements are present in a minor amount.

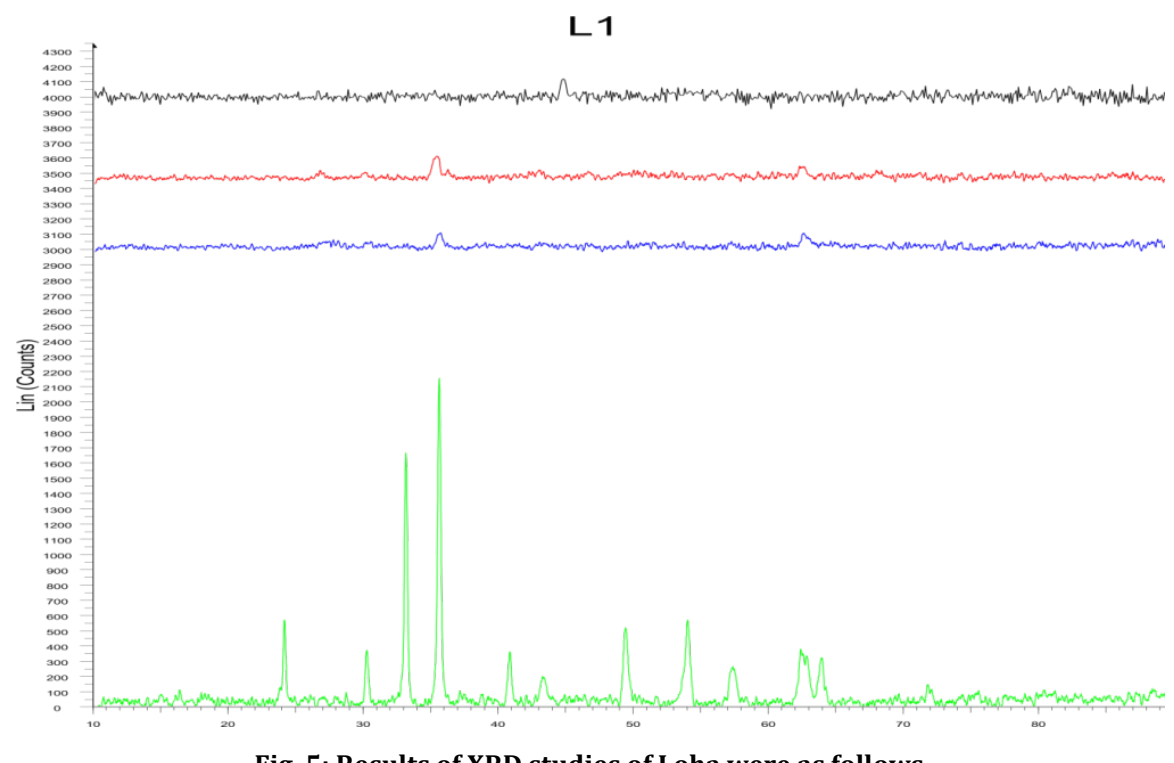

Fig. 5: Results of XRD studies of Loha were as follows

\section{2-Theta-scale}

L1-File: L1. raw-Type: 2Th/Th locked-Start: 5.000-End: $90.023^{\circ}$ Step: $0.100^{\circ}$-Step time: 35.4 s-Temp.: $25^{\circ} \mathrm{C}$ (Room)-Time Started: 12 s-Anode: $\mathrm{Cu}-\mathrm{WL}$ 1: 1.540 perations: Y Scale Add 1000 | Y Scale Add 1000 | Y Scale Add 1000 | Y Scale Add 1000 | Smooth 0.150 | Background 1.000,1.000 | Import

L2-File: L2. raw-Type: $2 \mathrm{Th} / \mathrm{Th}$ locked-Start: $10.000^{\circ}$-End: $89.995^{\circ}$ Step: $0.021^{\circ}$-Step time: 35.4 s-Temp.: $25^{\circ} \mathrm{C}$ (Room)-Time Started: 15 s-Anode: Cu-WL1: 1.50perations: Y Scale Add 458 | Y Scale Add 1000 | Y Scale Add 1000 | Y Scale Add 1000 | Smooth 0.150 | Background 1.000,1.000 | Import

L3-File: L3. raw-Type: 2Th/Th locked-Start: $10.000^{\circ}$-End: $89.995^{\circ}$ Step: $0.021^{\circ}$-Step time: $35.4 \mathrm{~s}$-Temp.: $25^{\circ} \mathrm{C}$ (Room)-Time Started: $8 \mathrm{~s}-$ Anode: Cu-WL1: 1.540perations: Y Scale Add 1000 | Y Scale Add 1000 | Y Scale Add 1000 | Smooth 0.150 | Background 1.000,1.000 | Import

L4-File: L4. raw-Type: $2 \mathrm{Th} / \mathrm{Th}$ locked-Start: $10.000^{\circ}$-End: $89.995^{\circ}$ Step: $0.021^{\circ}$-Step time: $35.4 \mathrm{~s}$-Temp.: $25^{\circ} \mathrm{C}$ (Room)-Time Started: 0 s-Anode: Cu-WL1: 1.540perations: Smooth 0.150| Background 1.000,1.000 | Import

Peaks in XRD analysis of all the four samples of Loha a were matching with Iron oxide right from Ashuddha Loha (L1), Samanya shodhit Loha (L2), Vishesh Shodhit Loha (L3), and Loha a Bhasma (L4). L4 has major XRD characteristic peaks at two theta angles of $30,35,43,54,57$, and 63 which corresponds to 220,311 , 400, 422, 511, and 440 indices respectively. L1, L2, and L3 have peaks at $31,36,44,57$, and 63 which corresponds to the iron oxide XRD pattern with indices at $220,313,400,422$, and 440 . The difference was observed in the crystalline phase, which has changed from tetragonal (L1, L2, and L3) to Cubic structure (L4). The peaks are intense, sharp, and well defined in the XRD pattern of Loha a Bhasma. The intense peaks represent the highly crystalline form of the compound (L4); the heat treatment has adversely affected the crystallinity of the compound and changes it to cubic form.

According to the XRF studies of Loha a Bhasma, it contains Fe203 $88 \%$, Silica in $4.87 \%$, and other elements such as $\mathrm{K}, \mathrm{Ca}, \mathrm{P}, \mathrm{AL}, \mathrm{O}, \mathrm{Ma}$, $\mathrm{Zn}$, in trace amounts.

\section{DISCUSSION}

The XRD and XRF studies of 5 iron-containing drugs and their intermediates revealed interesting findings. These procedures brought a change in the elemental composition of medicinal raw material. The extensive heat treatments and other procedures on raw materials of Ayurvedic drugs change their structure and composition. The XRD data has revealed that some elements were removed, changed, or minimized after Shodhana and Marana procedures. This clearly shows the effectiveness of the adopted pharmaceutical procedures.

In some samples in the above study, although no constitutional change is observed in the processed material, the brittleness of the material was observed to increase notably at the end of Shodhana. An increase in brittleness is known to facilitate further processing of Marana in such cases. 
It is believed that the use of different medicinal liquids in the form of decoctions and expressed juices for grinding the raw materials to facilitate pharmaceutical processing like Shodhana and Marana are responsible for the therapeutic action of the end product Bhasma. These Bhasmas are used with different adjuvants in medical practice by the Ayurvedic practitioners to derive different therapeutic effects. These processes make this one single end product able to be used in various conditions with different adjuvants. They make them a broad spectrum Ayurvedic drug.

XRD data has revealed that there is a change in the arrangements of the lattice structure of crystals. The amount of crystallinity has increased. This is important because the bioavailability of the drug in the body depends upon its structure. In some cases (L4 and S3), major changes in crystal structure have been observed. This could be the result of the co-crystallization of compounds. Co-crystals are multicomponent crystalline solids that can alter the Physicochemical properties of solids. They can increase or decrease the solubility of the drug compounds depending on the interaction between the solids. The observed change in XRD pattern for L4 and S3 possibly be a result of crystallization between phenolic compounds that can further be evaluated in a separate study.

Sharp intense peaks and clear smooth graphs in XRD of the final products compared to raw material and intermediates denote the uniform homogeneous phase of the final drug. This is achieved with the help of extensive Shodhana and Marana procedures. These treatments turn raw material into the final drug of acceptable quality and efficacy.

A common pattern regarding the change in the chemical constitution of all 5 drugs is observed in this study. This pattern indicates the transformation of all raw materials into their oxides. All the 5 ironcontaining raw materials were observed as being transformed into iron oxide following Marana. The oxides are known to be more acceptable in the body. Singh. N et al. have observed similar findings in their study on Loha Bhasma. According to them the ultimate phase of Loha Bhasma was observed as Iron oxide only [17].

After the cascade of these intense procedures, particle size of all these bhasma was reduced significantly. PAvani et al. have confirmed the particle size of Loha bhasma to be $28.7 \mathrm{~nm}$ [18].

Some part of every bhasma is in nanodomain also. There is a trend of preparation of metal nanoparticles with green synthesis method. The herbal juices of various plants are used for preparation of nanoparticles by green synthesis. Some of these plants are Ayurvedic herbs. P. Karan et al. have described the green biosynthesis of Magnetic Iron oxide Nanoparticles of Vitex Nigundo aqueous extract. They have stated that such biosynthetically prepared iron oxide nanoparticles can be a good source of alternative therapy for human diseases [19].

Patil Y et al. have recently reported the antimicrobial activity of magnetic iron nanoparticles. These magnetic iron nanoparticles were prepared by green synthesis process using leaf extract of medicinal plant Tridax Procumbens. These magnetic iron nanoparticles exhibited good antibacterial activity against gramnegative (E. Coli) bacteria [20].

This is clear that these finally prepared Bhasmas have some nanomaterial part in them. In our opinion these bhasmas can exibit superior pharmacological activity over the synthetically prepared nanoparticles. The resion reason is that they have gone throuogh extensive processes during their preparation. Hence their bioavailablity and bioassimilable nature could be superior to these synthetically prepared nanoparticles. This point needs a separate study for its evaluation. Further, these bhasmas are in clinical use since ages hence using these bhasmas will save lots of energy and time of various preclinical studies as their safety is already well explored in several different studies.

Although XRD studies revealed the major elemental phase composition of these Iron-containing drugs, XRF studies showed that each Bhasma and even Shuddha Gairika are compound formations comprising of multiple trace elements. This explains the broad therapeutic activity of these drugs. With no dispute, these microelements must have entered into the end products as a result of the use of different types of medicinal plant material used in Shodhana and Marana procedures. Bhargava S. also confirms the presence of several trace elements in Loha Bhasma [21] Ashwini A et al. also confirm the multielemental nature of Ayurvedic bhasmas. However they braught brought to notice that Bhasma prepared by different pharmacies differ in their elemental composition which can be attributed to different preparation procedures adapted by them pharmacies [22].

During the entire procedure of Shodhana and Marana, a strong possibility of the formation of herbal ligands with metals is felt. Such a possibility presents a new vista of therapeutically effective herbmetallic products. It is believed that the material adopts the therapeutic activity of the other material with which it is processed. Therefore, different plant materials are used in different Shodhana and Marana procedures. In this context, it is stated that,

"Tad Tad Vyadhyupyuktanam aushdhanam jale Ayasah prakshepam $\operatorname{prah}^{\prime \prime}($ A. P.3/246)

This means, as per the therapeutic requirement, one can use a different medium for Shodhana and Marana procedures in different diseases. This suggests that different herbal media impose a different effect on metals and minerals while processing.

The formation of different ligands from respective plants may be the reason for the difference in therapeutic activity of the drug product processed with it.

\section{CONCLUSION}

Pharmaceutical procedures such as Shodhana and Marana described in Ayurvedic classics, bring about a change in elemental composition and crystalline structure of the processed material. In the present study, such a change was studied and confirmed through XRD and $\mathrm{XRF}$ analysis. It is conclusively said that a change in the chemical constitution and crystalline structure is observed in the metal Loha(Iron) and iron-containing minerals Gairika (red ochre), Mandura (iron slag), Kasisa (green vitriol), and Suvarnamakshika (Copper pyrite) as a result of Shodhana and Marana. The basic iron element is transformed into its oxide. Apart from Iron oxide, the end product Bhasma is also observed to contain few trace elements like-K, Ca, P, AL, O, Ma, Zn. The presence of trace elements is deemed to be a result of the processing of the raw material with different types of plant materials.

\section{ACKNOWLEDGMENT}

The authors are thankful to the staff of ICT Matunga Mumbai and Varsha Bullion Lab Mumbai.

\section{FUNDING}

Nil

\section{AUTHORS CONTRIBUTIONS}

KAM performed all the pharmaceutical processes mentioned in the paper, conceptualized and wrote the manuscript. STA performed XRD analysis and worked as instrumentation expert. He added to the part of the manuscript related withinstrumentation. SSS Critical reviewed and edited the manuscript.

\section{CONFLICT OF INTERESTS}

The authors declare no conflict of interest in the publication of this manuscript.

\section{REFERENCES}

1. Rasatargini Sharma S. Motilal banarasi das publications. 11th ed. New Delhi; 2004. p. 22.

2. Kulkarni A. Samucchaya Rasaratna [reprint]. New Delhi: Meharchand Lachhamandas Publication; 2007. p. 45.

3. Naredran R. Role of gallic acid in the preparation of an ironbased Indian traditional medicine- lauha bhasma. Int J Pharm Pharm Sci. 2012;4:45-8.

4. Anonymous. The ayurvedic Pharmacopeia of India, Part 1. 1st ed. Vol. VII. Government of India; 2008. p. 5, 19. 
5. Rastargini Sharma S. Motilal Banarasi Das publications. 11th ed. New Delhi; 2004. p. 362.

6. Rastargini Sharma S. Motilal Banarasi Das publications. 11th ed. New Delhi; 2004. p. 495.

7. Rastargini Sharma S. Motilal Banarasi Das publications. 11th ed. New Delhi; 2004. p. 496.

8. Rastargini Sharma S. Motilal Banarasi Das publications. 11th ed. New Delhi; 2004. p. 497

9. Rastargini Sharma S. Motilal Banarasi Das publications. 11th ed. New Delhi; 2004; p. 498, 502.

10. Rasamrutam Yadavji T [reprint]. Chaukhamba Sanskrit Sansthan. Varanasi; 2007. p. 95.

11. Rastargini Sharma S. Motilal Banarasi Das publications. 11th ed. New Delhi; 2004. p. 95-6.

12. Kulkarni A. Samucchaya Rasaratna [reprint]. New Delhi: Meharchand Lachhamandas Publication; 2007. p. 30.

13. Rastargini Sharma S. Motilal Banarasi Das publications. 11th ed. New Delhi; 2004. p. 30-1.

14. Rastargini Sharma S. Motilal Banarasi Das publications. 11th ed. New Delhi; 2004. p. 99.

15. Rastargini Sharma S. Motilal Banarasi Das publications. 11th ed. New Delhi; 2004. p. 99-100.

16. Rastargini Sharma S. Motilal Banarasi Das publications. 11th ed. New Delhi; 2004. p. 596.
17. Singh N, Krc R, Nk P, Singh M. Chemical characterization of lauha Bhasma by X-ray diffraction and vibrating sample magnetometry. Int J Ayurvedic Med. 2010;1(3):143-9. doi: 10.47552/ijam.v1i3.26.

18. Tambur Pavani Tambur et al. A facile method of synthesizing ayurvedic medicine: Llauha bhasma (iron oxide nanoparticles) and its characterization TSch. Acad J Pharm Acol. 2015;4:51-3.

19. Karnan P, Anbarasu A, Deepa N, Usha R. Green biosynthesis of magnetic iron oxide nanoparticles of Vitex negundo aqueous extract. Int J Curr Pharm Sci. 2018;10(3):11-4. doi: 10.22159/ijcpr.2018v10i3.27220.

20. Patil YYY, Sutar VB, Tiwari AP. Green synthesis of magnetic iron nanoparticles using medicinal plant tTridax procumbens leaf extracts and its application as an antimicrobial agent against E. coli. Int J App Pharm. 2020;1:34-9. doi: 10.22159/ijap.2020.v12s4.40102.

21. Bhargava SSC, Reddy KR, Sastry GV. Identifications studies of Lauha Bhasma by X-ray diffraction and X-ray fluorescence. Ayu. 2012;33(1):143-5. doi: 10.4103/0974-8520.100332, PMID 23049200.

22. Ashwini A, Kerur B. Elemental analysis of ayurvedic drugs (bhasmas) by atomic absorption spectrometer. Asian J Pharm Clin Res. 2019;12:545-9. 